EESTI NSV TEADUSTE AKADEEMIA TOIMETISED. XI KOIDE

FOOSIKALIS-MATEMAATILISTE JA TEHNILISTE TEADUSTE SEERIA. 1962, NR. I

ИЗВЕСТИЯ АКАДЕМИИ НАУК ЭСТОНСКОИ ССР. ТОМ ХІ

СЕРИЯ ФИЗИКО-МАТЕМАТИЧЕСКИХ И ТЕХНИЧЕСКИХ НАУК. 1962, Na 1

\title{
МИНЕРАЛОГИЧЕСКАЯ ХАРАКТЕРИСТИКА ДИКТИОНЕМОВЫХ СЛАНЦЕВ МААРДУСКОГО МЕСТОРОЖДЕНИЯ
}

\author{
А. А. КОРДИКОВ
}

В низах ордовика Эстонин (точнее, в тремадокском ярусе) имеется весьма своеобразное осадочное образование, получившее, благодаря содержащейся в нем граптолитовой фауне и тонкой сланцеватости, наименование диктионемового сланца. По своему внешнему виду, а главным образом по фауне, эти сланцы представляют собой прекрасный маркирующий горизонт, и, хотя диктионемовая фауна встречается в подстилающих слоях оболовых песчаников, они легко выделяются как по своим литологическим особенностям, так и по вмещающим породам, в почве - слоям пирита, а в кровле - глауконитовым песком.

Не менее характерным признаком является-довольно равномерная, но в целом незначительная мощность, едва достигающая 4,9 м. В большинстве случаев она колеблется от 3 до 4 м. Подмечено, что в направлени с запада на восток мощность диктионемовых сланцев постепенно снижается. Так, в районе г. Нарвы она составляет уже только несколько сантиметров.

По валовому химическому составу диктионемовые сланцы представляют весьма интересное (как с научной точки зрения, так и с практической) образование, в котором на долю органического вещества приходится почти пятая часть их массы. Не менее своеобразна и силикатная часть породы. Так, содержание кремнезема в ней достигает довольно высокого для подобных образований значения (54\%). Непомерно велико содержание в породе окиси калия, достигающее почти $8 \%$, что говорит о гидрослюдистом составе тонкодисперсной части описываемых сланцев.

Имеются еще три особенности их валового химического состава. Так, содержание глинозема едва достигает $14 \%$, что для глинистых сланцев очень мало. Однако, если принять во внимание высокое содержание кремнезема и органического вещества, то разубоживание глинозема в общей массе породы станет совершенно понятным.

Укажем далее на несколько необычное соотношение основных форм железа в этой породе. Закись железа здесь заметно преобладает над окисью, что свидетельствует о восстановительной среде в процессе осадконакопления. Наконец, отметим сравнительно высокое содержание азота. Последнее заставляет предполагать животное происхождение органического вещества описываемых пород.

По внешним признакам диктионемовые сланщы легко выделяются из оболовой серии ордовика. Они обладают темно-бурой или почти черной окраской и весьма правильной и тонкой сланцеватостью, совпадающей со слоистостью. При выветривании порода расщепляется на тонкие листы. По своим гранулометрическим данным они представляют типичные глинистые сланцы, у которых средний диаметр слагающих мннеральных частиц около 0,005 мм. 


\section{Вещественный состав диктионемовых сланцев месторождения Маарду}

Қак известно, нормальная осадочная порода терригенного происхождения представляет собой весьма сложное многокомпонентное образование, в состав которого входят: 1) обломки различной степени дисперсности первичных магматических и мета морфических минералов - кварца, полевых шпатов, слюд и различных акцессориев; 2) глинистые минералы - продукты сложного физико-химического преобразования первичных магматических минералов; 3) органические остатки (точнее, скелеты организмов), органические и органо-минеральные соединения - битумы'и углистые вещества; 4) поглошенные катионы; 5) рассеянные и радиоактивные элементы.

Вполне понятно, что изучение приведенного и, кстати сказать, не совсем полного перечня компонентов осадочных пород требует применения различных методов иссле. дования, так как некоторые из них пригодны для одних компонентов, а некоторые для других. Определение вещественного состава осадочного образования типа глинистых сланцев проводится, как правило, при помощи микроскопов. Так, при изучении диктионемовых сланцев крупные частицы породы размером более 0,01 мм изучалис's при помощи поляризационного микроскопа, тогда как тонкодисперсные компоненты с размером частиц меньше 0,001 мм исследовались с помощью электронного микро скопа и термического анализа.

В задачу автора входило изучение минеральной части диктионемовых сланцев, на долю которой приходится более $80 \%$ массы породы. Для этой цели нам были представлены образцы из керна XV скважины месторождения Маарду. Каждый образец подвергся соответствующей подготовке путем изготовления петрографических шлифов или выделения тонкодисперсной фракции с размером частиц меньше 0,001 мм. Ниже приводится петрографнческое описание шлифов различных слоев диктнонемовых сланцев месторождения Маарду.

Образец с глубины 9,1-9,25 м скважины XV обладает алевропелитовой структурой и микрослоистой текстурой. ОН характеризуется чередованием тонких прослоев толщиной от 0,2 до 2 мм, в различной степени обогащенных красно-бурым пигментшым веществом. Под микроскопом в отдельных случаях удается наблюдать микроплойчатость. В просвечивающих участках можно установнть основные породообразующие минералы. Так, на долю кварца с размером частиц от 0,05 до 0,005 мм приходится не менее $60 \%$. Имеется кремнистое вещество в виде опала $(25 \%)$ и слюдистые частицы (редко серицит) в количестве 5-7\%. Спорадически наблюдаются хлорит, циркон. В качестве новообразований встречаются единичные призмочки турмалина *. Заметную роль играет пирит $(5-10 \%)$ с размером зерен до 0,005 мм и мельче. Распределен пирит по породе равномерно. В наиболее интенсивно окрашенных прослоях наблюдается тонкий угольный детрит $(1-2 \%)$. По всем данным образец следует отнести к алевропелитовым сланцам.

Следующий образец с глубины 10,9-11,05 м характеризуется пелитовой структурой и сланцевой текстурой. Под микроскопом порода имеет буро-красный цвет, обусловленный наличием пигментного вещества. Среди этой весьма тонкозернистой массы (10\%) видны слюдистые чешуйки, ориентированные в одном направлении. Встречаются редкие и очень мелкие зерна кварца. В качестве новообразований присутствует 7-10\% альбита (?). Примерно в таком же количестве обнаружен угольный детрит и редкие гелифицированные растительные остатки. Видна эмульсионная вкрапленность пирита.

Образец с глубины 12,2-12,3 м, также обладающий пелитовой структурой и сланцеватой текстурой, в отличие от предыдущих несколько обогащен чешуйками белой слюды. Встречаются единичные чешуйки хлоритизированного биотита. Присутствуют зерна кварца алевритовой размерности (до 10\%), которые так же, как и слюдки,

* По новым данным различных исследователей, турмалин может быть аутигенного происхождения. 

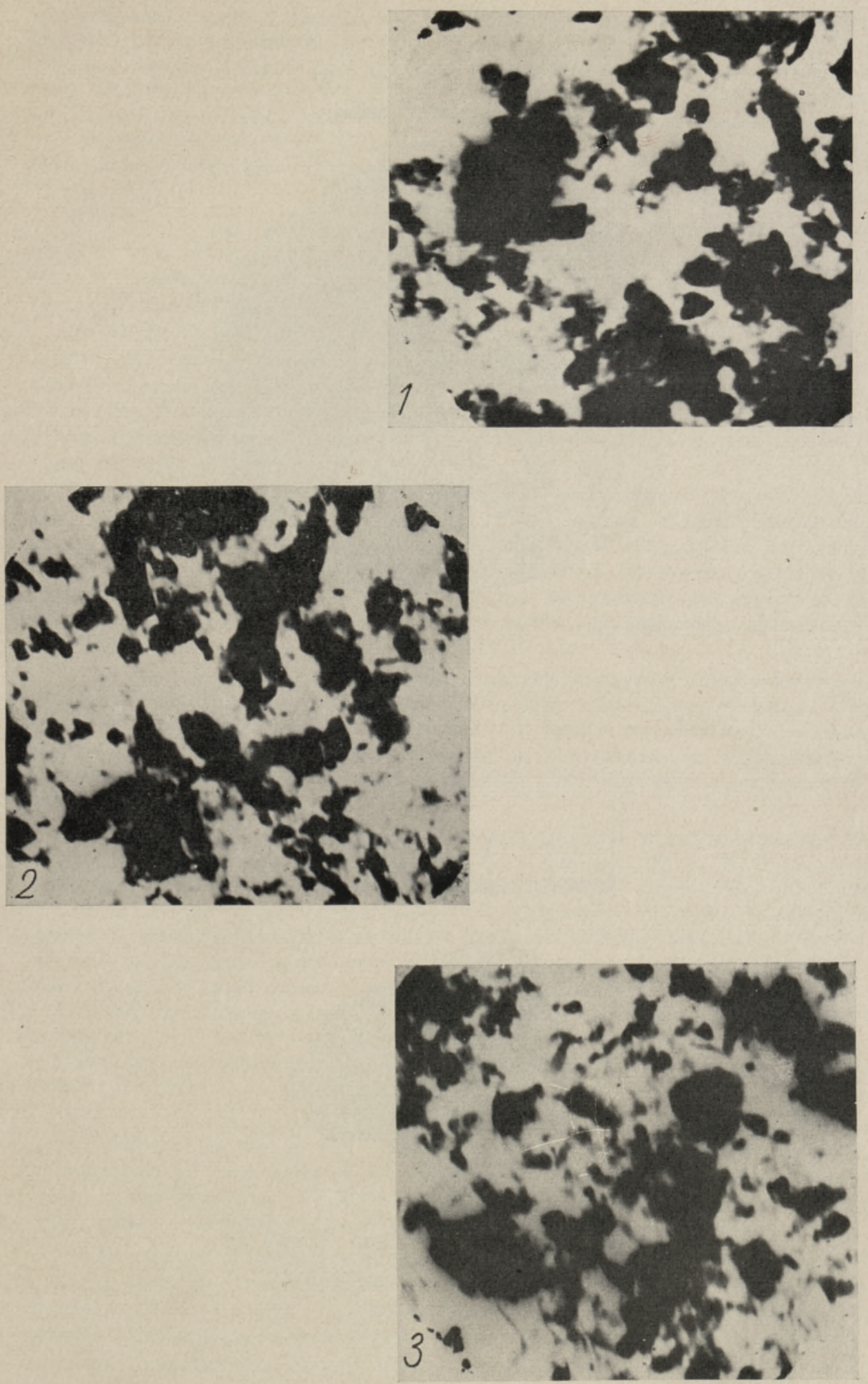

Фото 1. Тонкодисперсные фракции диктионемовых сланцев из XV скважины месторождения Маарду с глубины: $1-9,1-9,25 \mu ; 2-10,9-11,05 \mu$; $3-12,2-12,3$ м. (Увел. $6600 \times)$. 

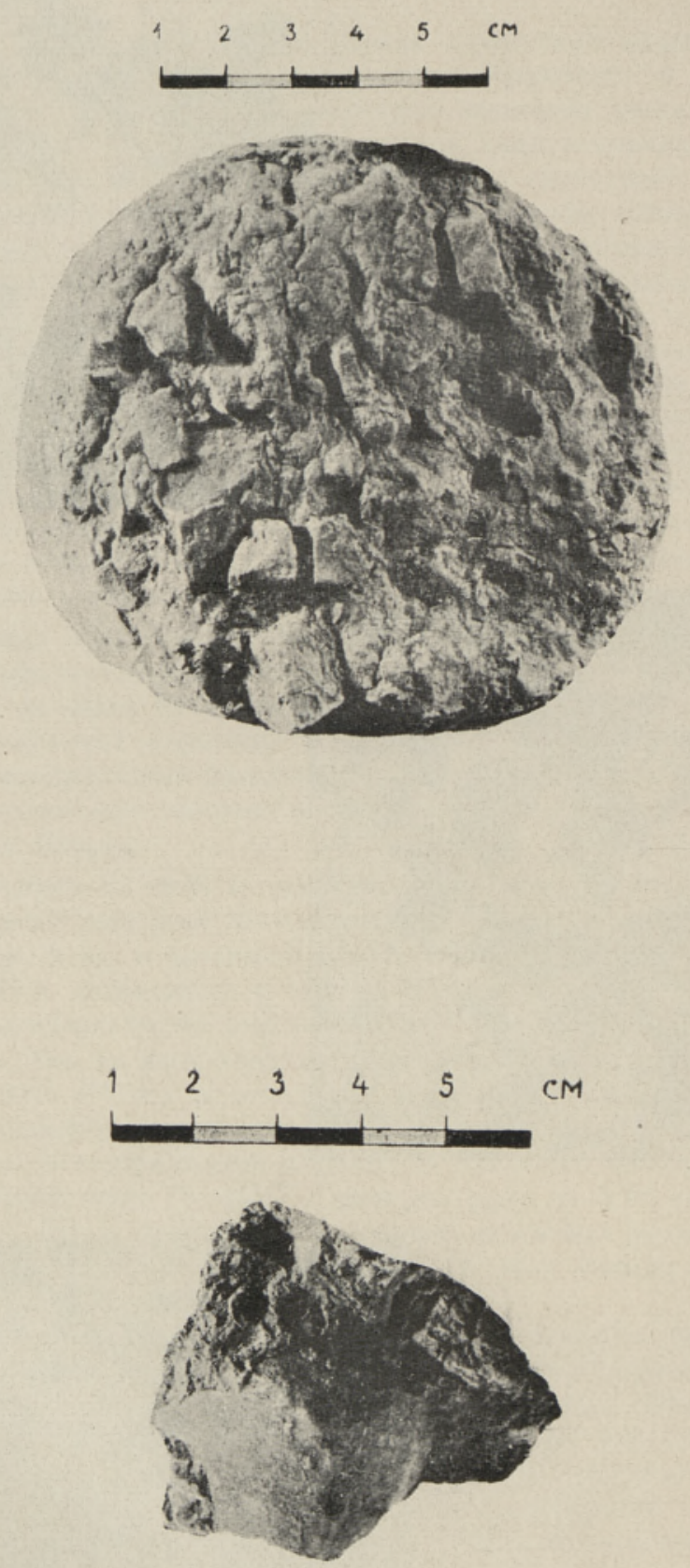

Фото 2. Обломки «глинистой» брекчии из $\mathrm{XV}$ скважины месторождения Маарду с глубины 11,0 м (0,7 нат. вел.). 
ориентированы своими длинными осями в одном направлении. Встречаются редкие чешуйки хлорита и единичные зерна глауконита (?). Порода в основном, как и в предыдущих случаях, сложена тонколистоватым красно-бурым пигментным веществом. среди которого видны обугленные и гелефицированные частички растительных остатков. Также имеется вновь образованный альбит (до $5 \%$ ) в виде мелких идиоморфных несдвойникованных зерен. В единичных случаях встречаются зерна альбита полисинтетического строения. Наблюдается тончайшая эмульсионная вкрапленность пирита.

У некоторых разновиднөстей опнсываемых пород содержание красно-бурого пигментного вешества достигает 50-60\%. К последнему примешивается почти столько же тонкодисперсного глинистого материала. По всем данным описанные породы следует отнести к глинистым сланцам.

Нз литературных источников известно, что алевритовая фракция диктионемовых сланцев слагается из кварца, калиевого полевого шпата, плагиоклаза и различных слюд. В тяжелой фракции этой же размерности установлены турмалин, циркон, апатит, гранат. В виде единичных зерен встречаются ставролит, эпидот, дистен, анатаз, окислы и гидроокислы железа, амфиболы и пироксены. Среди глинистых минералов называют иллит и монтморнллонит.

Тонкодисперсные фракции породы с размером частиц меньше 0,001 м изучались нами под электронным микроскопом. Перед этим исходный образец размачивался в воде, а затем осторожно растирался резиновым пестиком. Из растертой массы приготавливалась суспензия, из которой путем многократной декантации удалялись частицы меньше 0,001 мм. Последние изучались под электронным микроскопом и при помощи термического анализа. Органическое вещество предварительно уничтожалось перекисью водорода $(10 \%)$.

Под электронным микроскопом частицы указанной фракции имеют вид слегка вытянутых полупрозрачных чешуек (фото 1). Часто наблюдаются частицы более или менее изометричной формы. Все признаки, а именно: незначительная толщина, четкость контуров зерен и некоторое удлинение их - указывают на гидрослюдистый состав фракцин. В виде незначительной примеси в ней встречаются отдельные обломки кварца.

При термическом анализе глинистое вещество, с размером частиц меньше $0,001 \mathrm{мm.}$ претерпело пять эндотермических реакций: 1) в интервале. от 20 до $100^{\circ} \mathrm{C}$, довольно интенсивная, связана с поглощением тепла при удалении гигроскопической воды; 2) между $100-200^{\circ}$ с максимумом около $115^{\circ}$, обусловлена удалением межпакетной воды; 3) в интервале температур от 500 до $600^{\circ}$, очень незначительная по интенсивности, но с весьма резким максимумом около $510^{\circ}$, вызвана, по всей вероятности, переходом кварца из одной формы в другую; 4) очень незначительная по интенсивности, но с резким максимумом около $605^{\circ}$, принадлежит основному минералу и связана с удалением кристаллизационной воды; 5) слабая реакщия при $900^{\circ}$, достаточно продолжительная по времени, соответствуюшая, видимо, перестройке молекулы исследуемого вещества.

Кроме указанных реакций, имеются две экзотермических остановки: первая из них, в интервале от 250 до $450^{\circ}$, обусловлена выгоранием органического вецества. Интенсивность ее незначительна, что вызвано, как уже отмечалось, почти полным уничтожением органического вещества перед анализом. Вторая, с максимумом около $1000^{\circ}$, связана с разрушением незначительной примеси каолинита (фиг. 1).

Таким образом, наличие указанных реакций, их сочетание и интенсивность свщдетельствуют о гидрослюдистом составе фракции, в которой в качестве примесей присутствуют кварц, каолинит и органическое вещество. Наличие в тонкодисперсной фракции диктионемовых сланцев Әстонии монтмориллонита не подтвердилось. Нахождение ето в описываемых породах вообще сомнительно. Вполне возможно, что монтмориллонит был установлен ошибочно на основании термограмм необычного типа. 
Нами был проведен термический анализ так называемой «средней пробы», который показал некоторое отличие от остальных термограмм: вместо двух обычных эндотермических реакций при 510 и $605^{\circ}$ здесь фиксируется одна с максимумом при $550^{\circ}$.

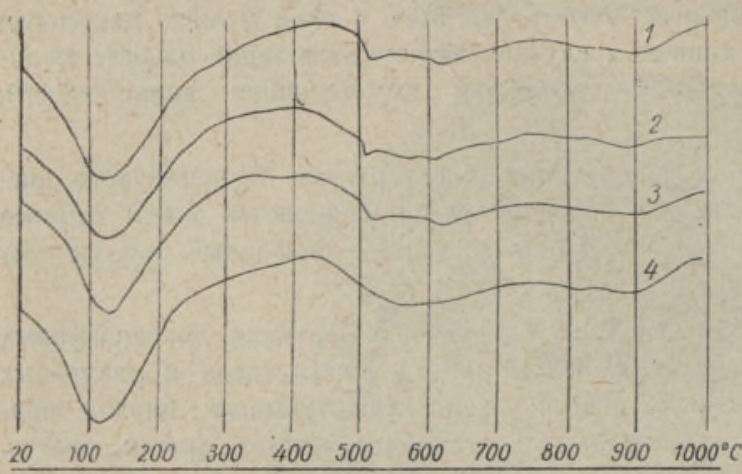

Фиг. 1.

Қривые нагревания тонкодисперсной фракции диктионемовых сланцев из XV скважины месторождения Маарду с глубины:

$$
\begin{aligned}
& 1-9,1-4,25 \mathrm{м} \\
& 2-10,9-11,05 \mathrm{м} \\
& 3-12,2-12,3 \mathrm{м} \\
& 4-\text { средня проба. }
\end{aligned}
$$

В случае более значительного содержания межпакетной воды такая термограмма может быть признана монтмориллонитовой.

\section{Генезис диктионемовых сланцев}

Наличие в диктионемовых сланцах Эстонии граптолитовой фауны не оставляет ни малейшего сомнения в их морском происхождении. Более того, тончайшая слоистость и высокое содержание тонкодисперсных глннистых фракций указывают как будто на отложения открытого и, следовательно, достаточно глубоководного моря. Однако, наряду с этими, казалось бы, бесспорными признаками имеются факты, отрицающне глубоководный характер отложения описываемых сланцев. Выше, во вступительной части, уже обращалось внимание на необычное соотношение в диктионемовых сланцах Эстонни окиси и закиси железа. Так, по данным, опубликованным А. Луха, содержание закиси железа в диктионемовых сланцах превосходит содержание окиси от 7 до 18 раз. Там же приводятся сведения о наличии в них довольно значительного количества сернистого железа $(3,25-4,5 \%)$. Согласно современным представлениям, повышенное содержание органнческого вещества и закиси железа, а также наличие сернистого железа в виде пирита свидетельствуют о восстановительной среде осадкообразования и о низком содержании кислорода в воде. Вполне естественно, что водоем, содержащий незначительное количество кислорода, не мог быть открытым морем, ибо там, как известно, всегда имеются морские течения и вертикальная циркуляция водных масс, приводящие к поглощению кислорода воздуха в количествах, вполне достаточных для поддержания органической жизни и уничтожения (окисления) органических остатков. Отсюда становится понятным высокое содержание органического вещества в диктионемовых сланцах, которое могло сохраниться в осадке шри низком содержании кислорода в придонных водах в условиях сероводородного брожения. С последним процессом связано образование аутигенного пирита в сланцах.

В свете всех этих данных напрашивается вывод о том, что днктионемовые сланцы Эстонии иредставляют- собой отложения сравнительно небольших морских водоемов, значительно изолированных от морских течений и имеющих затрудненную связь с открытым морем. Надо полагать, что это были морские лагуны.

Весьма интересный факт был обнаружен нами при просмотре керна XV скважины месторождения Маарду. Так, на глубине 11,0 м наблюдается прослой мощностью до 5 см, представляющнй собой своеобразную «глинистую» брекчию. Вмещаю-

* А. Луха, Полезные ископаемые Эстонской ССР. Тарту, ГИЗ «Научная литеparypa», 1948. 
щие слои - обычные тонкозернистые глинистые сланцы. Брекчия представлена слегка окатанными обломками тех же глинистых сланцев, сцементированными глинистым матерналом. Обломки имеют изометричную форму и размеры по нанбольшей оси от 1 до 3 см (фото 2). Такая брекчня могла образоваться только в зоне волноприбойной деятельности моря, и, следовательно, она характеризует мелководные условия осадкообразования диктионемовых сланцев. Уместно напомнить, что в слоях диктионемовых сланцев имеются песчаники и, наоборот, в подстилающих оболовых песчаниках встречаются глинистые сланцы.

На основании сказанного можно прийти ко второму выводу: осадкообразование диктионемовых сланцев происходило в прибрежно-морских условиях, в водоемах (лагунах) очень незначительной глубины. Наличие «глинистых брекчий, а также прослоев песпаников, быстро сменяющихся тонкодисперсным глинистым сланцем, говорит - значительной мобильности дна моря. Быстрые и кратковременные поднятия морского дна приводили прибрежные участки его в зону прибоя и создавали условия для отложения грубых осадков - песков и даже брекчий. В более поздние эпохи морское дно опустилось до глубины примерно 200 м, о чем свидетельствуют отложения с глауконитом (образующиеся, как известно, на глубинах до 200 м), восстановилась нормальная связь лагун с открытым морем и создался нормальный кислородный режим, в условиях которого прекратились накопление органического вещества н образование пирита. Создались условия для накопления глауконитовых песков, а затем органогенных карбонатных отложений. Появился богатый животный мир, но остатки его уже не могли накапливаться в значительных количествах, так как кислородный запас водных масс был уже достаточно велик для окисления (уничтожения) органического вещества.

Резюмируя все сказанное, можно постронть следующую рабочую гипотезу: диктионемовые сланцы Эстонии, заключающие граптолитовую фауну тремадока и содержащие до $20 \%$ органического вещества, что делает их энергетическим сырьем, представляют собой отложения мелководных морских лагун с весьма ограниченной связыо с открытым морем и очень-слабой гидродинамической активностью. Последние два обстоятельства привели, с одной стороны, к возникновению восстановительной среды и тем самым накоплению значительного количества органического вещества и, с другой, к накоплению больших количеств тонкодисперсного глинистого материала. В резульгате последующего опускания морского дна до глубин около 200 м прекратилось существование лагун, восстановились нормальный кислородный режим и гидродинамическая активность. Қак следствие этого, прекратилось накопление органического вещества и больших масс тонкодисперсного глинистого материала. Наступили условия для накопления глауконитовых песков, а несколько позднее, при дальнейшем опускании дна моря, и органогенных известняков.
Институт энергетики
Академии наук Эстонской ССР
Поступила в редакцию
31. XII 1960

\section{MAARDU DIKTUONEEMAKILDA MINERALOOGILINE KARAKTERISTIKA}

\section{Resümee}

\section{A. Kordikov}

Maardu diktüoneemakilda koostist, samuti tema struktuurilisi ja tekstuurilisi iséärasusi uuriti uuemate termograafiliste, optiliste ja elektronmikroskoopiliste meetodite abil. Polarisał'sioonmikroakoopimisel tehti kindlaks, et kōnesoleval diktüoneemakildal on aleuropeliitne struktuur ja kiltjas tekstuur. Talle on iseloomulik peliidi tugevasti savika (tera suurus alla $10 \mu$ ) fraktsiooni ülekaal. Sellele fraktsioonile lisanduvad mitmesuguse mineraalse koostisega $10-25 \mu$ suurused terad. Proovides leiti kvartsi, kaaliumpäevakivi, plagioklassi ja mitmesuguseid vilke, näiteks kloriidistunud biotiiti, muskoviiti, söe detriiti $(1-2 \%)$, punakaspruuni pigmenteerivat orgaanilist ainet ja gelifitseeritud 
taimejäänuseid. Autigeensetest mineraalidest esinevad opaal, kloriit, seritsiit, püriit, albiit, aktsessoorsetest - tsirkoon, turmaliin, apatiit, granaat. Stauroliit, epidoot, disteen, anataas, raudoksüüd ja raudhüdroksüüdid, amfüboolid ja pürokseenid esinevad üksikute teradena.

Peendispersse fraktsiooni elektronmikroskoopimisel tehti kindlaks, et ta koosneb oluliselt hüdrovilkudest, milledele tähtsusetul määral lisandub kvartsi. Termograafilised uurimised võimaldasid peendispersse komponendi mineraalset koostist teatud määral täpsustada: täiendavalt avastati kaoliniiti ja orgaanilist ainet.

Struktuurilised iseärasused, nagu peendisperssus, savikast kildast veidi ümardunud oligomiktsete settebretšade olemasolu ja suhteliselt kôrge orgaanilise aine ja raud(2) oksüüdisisaldus lubavad autoril arvata, et Maardu diktüoneemakildas on meil tegemist rannalähedase moodustisega.

Ainult aeg-ajalt avamerega ühenduses olevatele hanistaatilistele tsoonidele omastes laguunides vôis tekkida hapniku puudujääk ja seejärel taandav keskkond, mille toimel intensiivselt moodustusid ja kogunesid raud(2) ühendid. Tekkis olukord, milles orgaaniline aine intensiivselt kogunes ja konserveerus.

Diktüoneemafaunaga veebasseinide madalveesust tōestab settebretšade ja liivakivivahekihtide esinemine kildas.

\author{
Eesti NSV Teaduste Akadeemia \\ Energeetika Instituut
}

Saabus toimetusse 31. XII 1960

\title{
THE MINERALOGICAL CHARACTERISTICS OF MAARDU DICTYONEMA SHALE
}

\section{A. Kordikov}

\section{Summary}

The composition of Maardu dictyonema shale as well as its structural and textural peculiarities were studied by means of the latest thermographic, optical and electronmicroscopical methods. By polarisational microscopy it was stated that this dictyonema layer has an aleuropelitic structure and shistose texture. Typical of it is the pelitic predominance (the size of the grain being below $10 \mu$ ). In addition to this fraction there occur some grains (their size varying between $10-25 \mu$ ) of mineral composition. In the samples there proved to be quartz, kalifeldspar, plagioclase and different micas, e.g. chlorite biotite, muscovite, carboniferous detrite $(1-2 \%)$, and some pigmentic organic matter as well as gelose remnants of plants. Of authigenous minerals, there occur opal, chlorite, hydromica, pyrite, albite, and of accessory minerals - zircon, tourmaline, apatite and garnet. Granatite, epidote, disthen, anatase, oxide of iron and hydroxides of iron, amphiboles and pyroxenes occur as single grains.

At the electron-microscopy of the fine-dispersed fraction it was stated that it consists mainly of hydromicas and inconsiderable quantities of quartz. By means of thermographic methods it was possible to define the mineralogical composition of the fine-dispersed component with greater precision, and thus the presence of kaolinite and organic matter was detected.

The structural peculiarities, e.g. the finely dispersed structure, the presence of oligomicaceous, well-rounded precipitated breccias of argillaceous shist and the relatively high content of organic matter and iron dioxide allow the author to assume that Maardu dictyonema shale is a littoral formation.

The lack of oxygen and thereafter a retreating environment could have originated only in lagoons peculiar of zones that were from time to time connected with the open sea, and it was here that the oxygen compounds were intensely formed and the organic matter accumulated and was conserved.

The shallow-water condition of basins with dictyonema fauna is proved by the occurrence of precipitation breccias and sand interstratifications in the shist.

Academy of Sciences of the Estonian S.S.R. Institute of Energetics 